\title{
Canine Inflammatory Mammary Carcinoma as a Promising Model for Cancer Pathology and Anticancer Drug Development: Lessons from a Case Series
}

\author{
(1) Sanaz RISMANCHI,' () Pejman MORTAZAVI,' (1) Samad MUHAMMADNEJAD² \\ 'Department of Pathobiology, Science and Research Branch, Islamic Azad University, Tehran-Iran \\ ${ }^{2}$ Gene Therapy Research Center, Digestive Diseases Research Institute, Tehran University of Medical Sciences, Tehran-Iran
}

\begin{abstract}
OBJECTIVE
The prognosis of Inflammatory Breast Carcinoma (IBC) in women is weaker than other types of breast cancer. Inflammatory Mammary Carcinoma (IMC) is a spontaneous breast malignancy in dog which, according to some scientific evidence, can be a good model for women's IBC studies. This study aimed to describe the clinical, pathological, immunohistochemistry characteristics and clinical findings of relapse in IMC compared with IBC.
\end{abstract}

\section{METHODS}

This study was a case series, and 10 dogs confirmed for IMC diagnosis were included. Their clinical and pathological parameters and recurrence findings and Disease-Free Survival Rate (DFS) were calculated, and paraffinic blocks were stained by ER, PR, HER2, Ki67, TP53 and COX2 markers and their relationships with DFS was obtained.

\section{RESULTS}

In $40 \%$ of cases the lymph nodes were involved. All tumors were high-grade and had $70 \%$ of vascular invasion and dirty margins. Evaluation with IHC showed only $10 \%$ of them were hormone receptor positive and 70\% were HER2 positive. Ki67 was high in all patients and HER2 and triple negatives molecular subtypes accounted for $70 \%$ and $30 \%$ of cases, respectively. $80 \%$ of cases were p53, and the COX 2 enzyme was positive in all cancers. Statistical analysis showed that DFS was associated with Ki67 expression and the risk of recurrence increased with the elevation of its expression.

\section{CONCLUSION}

In dogs, IMC mimics many of the clinical, pathological, and molecular characteristics of human IBC, and is likely to be a suitable model for comparative oncology studies.

Keywords: COX2 enzyme; disease-free survival; inflammatory breast carcinoma; inflammatory mammary carcinoma; molecular subtype.

Copyright $\odot$ 2021, Turkish Society for Radiation Oncology

\section{Introduction}

In 1814, Charles Bell first described inflammatory breast carcinoma $(I B C)$ as a terrible disease.[1] On the one hand, its clinical appearance was different from other common breast cancers, and, on the other, it was a deadly cancer.[2] IBC is said to be a clinicopathologic term and pathology alone cannot distinguish it from other breast carcinomas. Therefore, IBC should be diagnosed following clinical and pathologic findings.[3] 
In IBC, histopathologic findings are not specific, but one of the most important diagnostic hallmarks is dermal lymphatic invasion (DLI). However, DLI is also not specific and may be seen in other types of breast cancer.[4] Pathological and molecular studies showed that $90 \%$ of IBCs are invasive ductal carcinoma (IDC), and most are high grade.[5,6] Moreover, triple-negative and ERBB2 in IBC constitutes the most common molecular subtype. $[7,8]$

Surgical treatments are not very successful, and the risk of local recurrence and metastasis is high.[3,9] Current chemotherapy also does not significantly improve patients' living standards. Targeted therapies in this type of breast cancer are still underdeveloped,[2,9] although scientific evidence suggests a high expression of cyclooxygenase 2 (COX2) in the IBC. COX2 is one of the most important inflammatory mediators and plays a role in promoting neoplasm development. COX2 is also a prognostic factor in breast cancer and patients with overexpression of this enzyme in cancer tissue have a lower survival rate.[10]

Despite the complexity of the diagnosis and treatment of IBC, research in this area also presents challenges. Mouse models can never exhibit the clinicopathologic features of IBC. Although the IBC xenograft tumor models (cell lines isolated from pleural effusion of IBC) are biologically capable of mimicking the characteristics of human disease, they lack some of the pathological features such as dermal lymphatic invasion.[11-13]

In recent years, canine mammary cancer $(C M C)$ has been the focal point of cancer research, because CMC has many biological, pathological and behavioral parallels with human breast cancer $(H B C)$.[14] Inflammatory mammary carcinoma (IMC) is as rare as IBC and statistics show that it accounts for 1-3\% of all CMCs.[15] Some researchers believe that IMC also limits patients' lives and that surgical treatments are unsuccessful.[16]

One of the weaknesses of pet oncology studies is the challenge in assessing overall survival rate (OS) and disease-free survival (DFS) for the reason that follow-upped patients have many problems after diagnosis until relapse or death. In this case series study, we attempted to record patients accurately, and to obtain DFS, by precisely recording the information regarding clinical, surgical, and IMC pathology of the dogs. We then determined the molecular subtype of IMC and evaluated the diagnostic biomarkers of tumor proliferation status, p53 status, and COX2 enzyme expression in the cancerous tissue in order to compare the similarities and differences with IBC.

\section{Materials and Methods}

This study was a "case-series study" and the samples were selected from pet-animal pathology reports at the laboratory of Cancer Biology Research Center $(C B R C)$ of the Cancer Institute of Iran. Pathology reports from canine tumors were reviewed from 2014 to 2018. Basis of pathology reports was relied on the registry of "International Classification of Diseases for Oncology Registry $3^{\text {rd }}$ revision (ICD-O-3). Although this code is used in the human cancer registry system, its modified form can also be used in the pet animal cancer registry system.[17] Searches include C50.9 (coding for the canine mammary gland anatomical region) and histo-morphological codes M: 8010/3 (for epithelial tumor, malignant type) and M: 8530/3 (inflammatory mammary carcinoma) were selected. All pathologic reports were reviewed, and 14 IMCs that were definitive in their pathology report were selected and clinical and pathological records were reviewed. Some files had information deficiencies that were resolved by contacting the animals' owners and the veterinarians concerned. However, the records of 4 patients were excluded due to a lack of clinical information. Therefore, a total of 10 patients were included in this study. Patient information was recorded in the following three sections:

a. Patients' clinical records: The following parameters were determined: Patient records, the age, breast number involved, tumor laterality, tumor size (present in patient's clinical record or report), the status of axillary or inguinal lymph nodes (according to cytological or histopathologic information), postoperative complications, symptoms of clinical recurrence of cancer, DFS (Time from surgery to cancer recurrence), and the fate of the patient after recurrence was determined.

b. Pathology report: In the pathology reports of the patients, the following were stated: tumor histology (based on Goldschmidt classification),[15] tumor grade (based on Nottingham grading system),[15] dermo-lymphoid invasion status, vascular invasion status, necrosis \& microcalcifications status, and the status of surgical margins.

c. Study by Immunohistochemistry (IHC): Patients' slides were reviewed and an appropriate paraffin block was selected from each patient's tumor, and six 3-micron slides were prepared for IHC. After deparaffinization of the slides and tissue rehydration, the retrieval antigen stage was performed with a microwave. Neutral peroxidases were neu- 
tralized with oxygenated water, and after washing in buffered solutions, the primary antibodies (according to Table 1) were incubated with tissue sections for $60 \mathrm{~min}$ at room temperature. The slides were washed in PBS and the secondary antibody and Polymer HRP were added to the tissues using Bio-care medical kits. Finally, amplification was performed using DAB staining. Tissue staining was done with the hematoxylin-Harris method. Finally, tissue dehydration was performed using ascending alcohols and the slides were mounted after three changes of xylene container. Slides were studied under light microscopy. After the determination of estrogen receptor (ER), progesterone receptor (PR) and HER2 status, the molecular subtype status of the mammary tumor was determined. The proliferation index was determined by Ki67 marker, and p53 status was also determined. Furthermore, according to the modified Allred scoring system, expression of COX2 enzyme was evaluated and reported as negative, weakly positive, moderately positive, and strongly positive (Fig. 1).

d. Statistical analysis: Significance level was set at 0.05 . To assess the correlation between Ki-67 expression and DFS, we used linear regression analysis. DFS curves between different groups were assessed by log-rank (Mantel-Cox) test. All analyses were performed by Graphpad Prism 6.0.

Table 1 Characteristics of the IHC antibodies used in this study

No Antibody Company Catalog Number Dilution

\begin{tabular}{lcccc}
\hline 1 & ER & Biorbyt & Orb14796 & $1: 100$ \\
2 & PR & Biorbyt & orb106338 & $1: 100$ \\
3 & HER2 & Biorbyt & orb315778 & $1: 200$ \\
4 & Ki67 & Biocare Medical & APF3156AA.H & Ready to use \\
5 & TP53 & Biorbyt & orb389251 & $1: 100$ \\
6 & COX2 & Biocare Medical & SKU: 306 & $1: 200$ \\
\hline
\end{tabular}

ER: Estrogen receptor; PR: Progesterone receptor; HER2: Human epidermal growth factor receptor 2; TP 53: Tumor protein 53; COX2: Cyclooxygenase 2
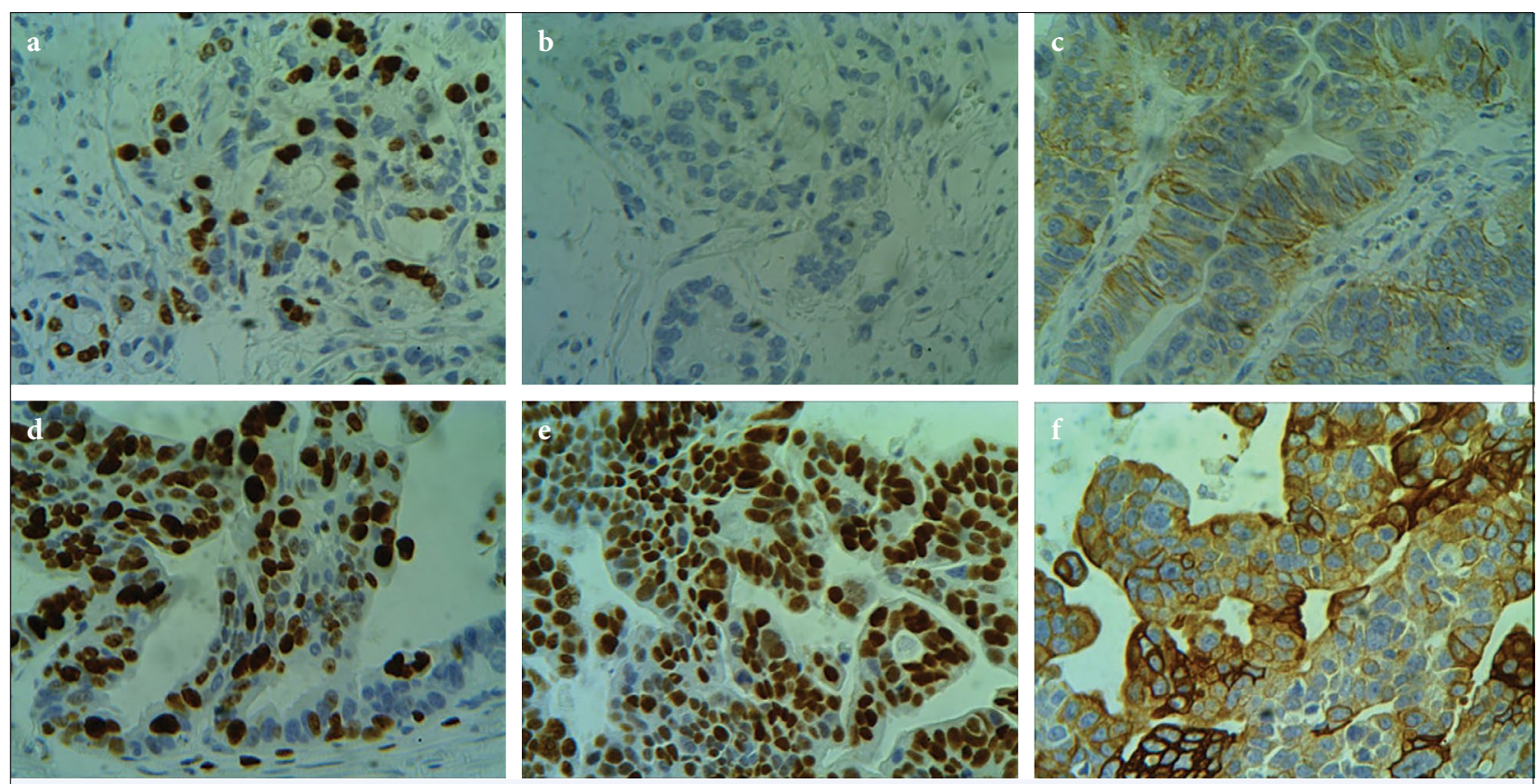

Fig. 1. Microscopic images of Inflammatory Mammary Carcinoma (IMC) on x400 magnification are shown as above. (a) This image was stained with ER marker and only in one of the studied IMCs were there immune-reactive nuclei in malignant cells. (b) As can be seen in the picture, PR was not reported positive in any of the studied IMCs. (c) This shows HER2 staining. In our study, 70\% of the membranes of malignant immune-reactive cells were marked with HER2 marker as moderate to strong. (d) All malignant nuclei in Ki67 showed high proliferation, and it is likely that the aggressive characteristics of IMC can be shown with this marker. (e) Evaluation of TP53 function in our study by IHC showed that in $80 \%$ of the studied tumors, the function of this tumor suppressor gene was impaired and probably one of the mechanisms of invasion and metastasis in IMC was somatic disorder of this gene. (f) The COX2 enzyme was expressed throughout the cytoplasm of malignant cells in this study and could possibly provide an opportunity for IMC treatment. 


\section{Results}

In this study, 10 female dogs with inflammatory mammary cancer were evaluated clinically, pathologically, immunohistochemically, and were followed up. The results of the study are described separately below.

1. Description of Clinical Condition: Dogs were ranging from 4 to 12 years old with a mean of $8.1 \pm 2.4$ years. For finding clinicopathologic relationships, they were divided into two groups of $<8$ years (younger cases) and $>8$ years (older cases). $50 \%$ of cases were $4-8$, and the other $50 \%$ were $8-12$ years (Table 2). From the laterality point of view, $60 \%$ of tumors happened in the left mammary gland $(M G)$ and the rest (40\%) were located in the right MGs. MG \#4 had the highest involvement on both sides (Table 2). The mean size of the tumors was $4.2 \pm 1.0 \mathrm{~cm}$ and based on TNM staining for inflammatory mammary cancer (IMC), all tumors were considered as T4,[18] irrespective of the size. From the surgical point of view, $60 \%$ of cases were operated for unilateral mastectomy and the rest were operated for simple mastectomy (Table 2). Presurgical cytologic evaluation and/or histopathologic evaluation of the surgical specimens revealed that lymph nodes were involved in 4 cases. In 4 cases they were not involved and there was no information accessible for the rest (20\%) (Table 2).

\begin{tabular}{lcc} 
Table 2 & $\begin{array}{c}\text { Clinical Aspects of Inflammatory mammary } \\
\text { carcinoma (IMC) }\end{array}$ \\
Parameter & Category & Percentage (\%) \\
\hline Age (4-12 Y/O) & $4-8$ & $3(30)$ \\
Tumor location & $8-12$ & $7(70)$ \\
Number of mammary gland & Left & $6(60)$ \\
& Might & $4(40)$ \\
& MG\#22 & $1(10)$ \\
& MG\#3 & $(20)$ \\
& MG\#4 & $6(60)$ \\
Tumor size & MG\#5 & $1(10)$ \\
& Up to 3 cm & $0($ Null) \\
Type of surgery & $3-5 \mathrm{~cm}$ & $6(60)$ \\
& Over than 5 cm & $4(40)$ \\
Regional lymph- & Unilateral mastectomy & $6(60)$ \\
node status & Simple mastectomy & $4(40)$ \\
& Free & $4(40)$ \\
& Involve & $4(40)$ \\
& Unclear & $2(20)$ \\
\hline
\end{tabular}

IMC: Inflammatory mammary carcinoma; MG: Mammary gland
2. Description of histopathologic condition: Results of the study demonstrated that the tumor histology of tubulopapillary carcinoma had the highest frequency; tubular carcinoma and comedo type carcinoma were placed in the next categories. From the grading system point of view, $60 \%$ of tumors were in grade III and the rest of them were in grade II. No tumor was classified as grade I (Table 3). Dermo-lymphoid invasion was found as a microscopic finding in $100 \%$ of

Table 3 Histopatologic and IHC Aspects of Inflammatory mammary carcinoma (IMC)

\begin{tabular}{|c|c|c|}
\hline \multirow{3}{*}{$\begin{array}{l}\text { Parameter } \\
\text { Tumor } \\
\text { histology }\end{array}$} & \multirow{2}{*}{$\begin{array}{l}\text { Category } \\
\text { Tublo-papillary carcinoma5 }\end{array}$} & rcentage (\%) \\
\hline & & $(50)$ \\
\hline & Tubular carcinoma & $4(40)$ \\
\hline & Comedo type carcinoma & $1(10)$ \\
\hline \multirow{3}{*}{$\begin{array}{l}\text { Tumor } \\
\text { grade }\end{array}$} & Grade I & 0 (null) \\
\hline & Grade II & $4(40)$ \\
\hline & Grade III & $6(60)$ \\
\hline \multirow{5}{*}{$\begin{array}{l}\text { Dermo- } \\
\text { lymphoid } \\
\text { invasion } \\
\text { Lymphovascular } \\
\text { invasion }\end{array}$} & Present & $10(100)$ \\
\hline & Absent & 0 (Null) \\
\hline & Present & $6(70)$ \\
\hline & Absent & $3(30)$ \\
\hline & Equivocally & $1(10)$ \\
\hline \multirow[t]{2}{*}{ Necrosis } & Present & $7(70)$ \\
\hline & Absent & $3(30)$ \\
\hline \multirow[t]{2}{*}{ Microcalcification } & Present & $3(30)$ \\
\hline & Absent & $7(70)$ \\
\hline \multirow{2}{*}{$\begin{array}{l}\text { Surgical margin } \\
\text { status }\end{array}$} & Free & $7(70)$ \\
\hline & Involve & $3(30)$ \\
\hline \multirow[t]{2}{*}{ ER } & Positive & $1(10)$ \\
\hline & Negative & $9(90)$ \\
\hline \multirow[t]{2}{*}{ PR } & Positive & 0 (Null) \\
\hline & Negative & $10(100)$ \\
\hline \multirow[t]{2}{*}{ HER2 } & Positive & $7(70)$ \\
\hline & Negative & $3(30)$ \\
\hline \multirow[t]{3}{*}{ Ki67 } & Negative (up to $4 \%$ ) & 0 (Null) \\
\hline & Moderate (5-14\%) & 0 (Null) \\
\hline & High (over than 15\%) & $10(100)$ \\
\hline \multirow{4}{*}{$\begin{array}{l}\text { Molecular } \\
\text { subtype }\end{array}$} & Luminal A & 0 (Null) \\
\hline & Luminal B & $1(10)$ \\
\hline & HER2 & $6(60)$ \\
\hline & Triple negative & $3(30)$ \\
\hline \multirow[t]{2}{*}{ TP53 } & Positive & $8(80 \%)$ \\
\hline & Negative & 0 (Null) \\
\hline \multirow[t]{4}{*}{$\operatorname{cox} 2$} & Negative (0) & 0 (Null) \\
\hline & Weak (1+) & 0 (Null) \\
\hline & Intermediate $(2+)$ & $2(20)$ \\
\hline & Strong $(3+)$ & $8(80)$ \\
\hline
\end{tabular}

IMC: Inflammatory mammary carcinoma; ER: Estrogen receptor; PR: Progesterone receptor; HER2: Human epidermal growth factor receptor 2; TP53: Tumor protein 53; COX2: Cyclooxygenase 2 
IMC tumors and this hallmark was seen in all samples (Table 3). Based on the pathology reports of the patients, $70 \%$ of tumors were vascular invasion positive and in $20 \%$, it was negative while it was equivocal in 1 case. On the other hand, in $70 \%$ of the patients, tumor necrosis was observed, but micro-calcification happened only in $30 \%$ of cases (Table 3). Evaluation of tumor margins showed that $70 \%$ of patients possessing surgical margins were involved in 1 or more directions, while only 3 patients were detected as surgical margin-free (Table 3 ).

a. Description of the situation of IHC: Evaluation and reporting of ER \& PR: The interpretation method was accomplished using All-Red Scoring System. Immunoreactivity above $1 \%$ of malignant foci was taken as positive cases. Our study showed that progesterone receptors were absent in all 10 tumors, and tumor growth was estrogen-receptor dependent only in 1 patient (Table 3).

b. Evaluation of HER2: In this research work, $70 \%$ of patients showed an over-expression of HER2 protein and the microscopic pattern +3 , whereas $30 \%$ of them demonstrated negative and equivocal scores (Table 3).

c. Evaluation of Ki67: Based on the findings of the present study, the proliferation coefficient ranged between 15-35\%, and, according to the St. Gallen Guideline (2011), all mammary gland tumors were in the situation of a highly proliferation index (Table 3).

d. Evaluation of molecular subtype: In this study, $60 \%$ of patients were categorized in the HER2 group and $30 \%$ in the triple-negative subgroup. Only one patient was in luminal B molecular group while no one was in Lumina A (Table 3).

e. Evaluation of TP53 gene: In this study, $80 \%$ of patients were recognized as IHC positive and 2 patients were reported as negative (Table 3 ).

f. Evaluation of COX2 enzyme: The results of this study showed that the expression of COX2 enzyme was strong in $80 \%$ of IMCs and intermediately positive in the remaining $20 \%$. Neither negative nor weakly positive case was found among the patients (Table 3).

4-Description of post-operative complications, recurrence of clinical findings \& metastasis, DFS rate and patient outcome: The results of post-operative follow-up showed that surgical complications were observed in $50 \%$ of cases $(n=5)$, so that the main problems after surgery were related to the opening of sutures and inflammation of the urethra. In one case, infectious and secretory lesions in the surgical area were reported (Table 4). Symptoms of recurrence in all cases were local recurrence, with $100 \%$ of animal owners appealing to the clinician for recurrence of skin lesions in the breast area. In one case (10\%), there was

Table 4 Postoperative complications, relapse, disease free survival rate and patient outcome

\begin{tabular}{|c|c|c|c|c|}
\hline Case & $\begin{array}{l}\text { Postoperative } \\
\text { complications }\end{array}$ & $\begin{array}{l}\text { Clinical findings after recurrence } \\
\text { and metastasis }\end{array}$ & $\begin{array}{l}\text { Disease free } \\
\text { survival (days) }\end{array}$ & $\begin{array}{l}\text { Patient outcome } \\
\text { after relapse }\end{array}$ \\
\hline 1 & $\begin{array}{l}\text { Open sutures and swelling } \\
\text { were created in the area }\end{array}$ & $\begin{array}{l}\text { Local recurrence, edema and } \\
\text { redness in skin }\end{array}$ & 63 & Euthanasia \\
\hline 2 & No & Recurrence of multiple lesions on the skin & 32 & Euthanasia \\
\hline 3 & No & $\begin{array}{l}\text { Recurrence and cough and } \\
\text { canonball in the right lung }\end{array}$ & 76 & Euthanasia \\
\hline 4 & $\begin{array}{l}\text { Problem with surgical wound } \\
\text { healing }\end{array}$ & $\begin{array}{l}\text { Nodular lesions on the skin with } \\
\text { redness of the skin }\end{array}$ & 88 & $\begin{array}{c}\text { Chemotrapy+COX2 } \\
\text { inhibitor }\end{array}$ \\
\hline 5 & $\begin{array}{l}\text { Open sutures and swelling } \\
\text { were created in the area }\end{array}$ & Numerous lesions on the skin & 75 & Euthanasia \\
\hline 6 & No & $\begin{array}{l}\text { Local recurrence, edema and } \\
\text { redness in skin }\end{array}$ & 34 & Unclear \\
\hline 7 & No & $\begin{array}{l}\text { Recurrence of multiple lesions of } \\
\text { tumors in the skin }\end{array}$ & 70 & Unclear \\
\hline 8 & $\begin{array}{l}\text { Open sutures and swelling } \\
\text { were created in the area }\end{array}$ & Local recurrence, edema and redness in skin & 27 & Euthanasia \\
\hline 9 & No & $\begin{array}{l}\text { Wounds and edema in the skin of the } \\
\text { surgical area }\end{array}$ & 40 & Euthanasia \\
\hline 10 & $\begin{array}{l}\text { Open sutures and swelling } \\
\text { were created in the area }\end{array}$ & $\begin{array}{l}\text { Recurrence of multiple lesions of tumors } \\
\text { in the skin }\end{array}$ & 18 & Unclear \\
\hline
\end{tabular}


a cough in addition to skin lesions; in this patient, Cannonball metastases were reported in the chest X-rays (Table 4). The term "DFS" in this paper relates to the number of days the dogs under lived free of a breast tumor, and this time interval was calculated from the day of surgery to the day the tumor was clinically proven to recur. In this study, the earliest and latest diagnosis of cancer recurrence was reported on 18 and 88 days after the surgery, respectively. The average DFS in this study was $52.3 \pm 24.7$ days (Table 4 ). The follow-up of patients showed that most dogs were euthanized after diagnosis of IMC recurrence (70\%), and only in one case chemotherapy-based treatment was performed together with a COX2 inhibitor; this single patient had died soon later due to septicemia. The final fate of $30 \%$ $(n=3)$ of patients was unknown (Table 4$)$.

\section{5- Data Presentation and Statistical Analysis: Regres-} sion analysis showed that there was an inverse relationship between Ki67 and DFS values, which was statistically significant ( $\mathrm{p}=0.0129 ; \mathrm{R} 2=0.5591$ (In other words, with the increase of tumor proliferation coefficient, the time of tumor recurrence had decreased (Fig. 2). Statistical analysis of Log-rank (Mantel-Cox) showed that there was no relationship between the expression of grade 2 and grade 3 COX 2 enzyme and DFS ( $\mathrm{p}=0.0512$; Median DFS in $2+=88$ days; Median DFS in $3+=35$ days). Statistical analysis of Log-rank (Mantel-Cox) showed that there was no relationship between the expression of grade 2 and grade 3 COX 2 enzyme and DFS

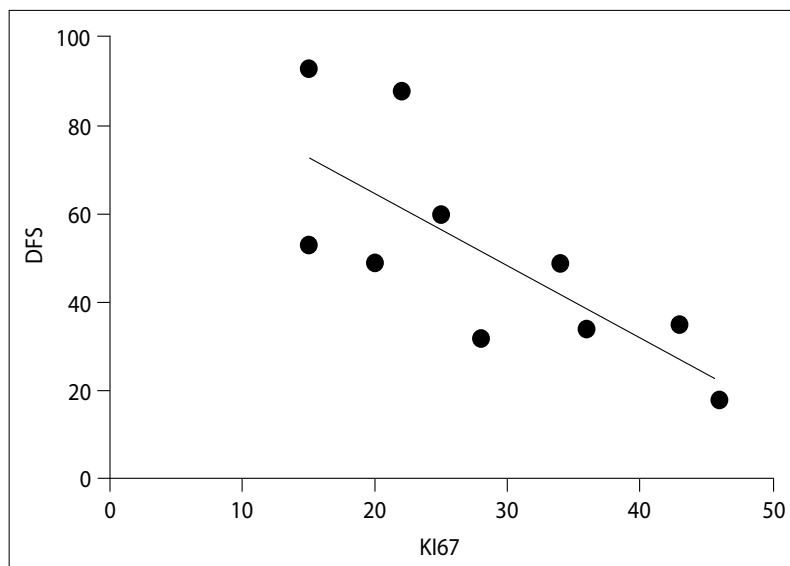

Fig. 2. Regression analysis between Ki67 (x axis) and DFS (y axis) values in canine with inflammatory mammary carcinomas. There was an inverse relationship between Ki67 and DFS values $(\mathrm{P}<$ $0.05)$. Regression coefficient $(\mathrm{r})=-0.7478 ; \mathrm{Y}=$ $\left(-1.633^{\star} \mathrm{X}\right)+97.48$.

DFS: Disease-free survival.
( $\mathrm{p}=0.0512$; Median DFS in $2+=88$ days; Median DFS in $3+=35$ days) (Fig. 3 ). Regarding the relationship between p53 and DFS, patients were first divided into two groups, p53+ and p53-, and the data were calculated based on mean and SEM, and then the means of two groups were compared using unpaired $t$ test. No significant statistical relationship was found between the two groups ( $\mathrm{p}=0.1954$; Median DFS in positive group $=42$ days; Median DFS in negative $=71$ days).

\section{Discussion}

In recent years, life expectancy in $I B C$ patients has somewhat increased. A 20 -year long study of a population of over 7,000 women with stage III IBC found that survival rates had increased in recent years and that one of the main reasons was the introduction of new pharmacotherapeutic agents.[19] The biology of cancer is very complex, and new laboratory facilities have created the conditions for researchers to be able to move cancer therapies to targeted therapy and individualized-therapy. However, the rate of death in IBC is higher than in comparison to other breast malignancies.[9]

Veterinarians reported a disease in dogs similar to that of IBC in women, and epidemiological and molecular evidence suggests that IMC may be similar with human IBC.[20] In this study, we investigated IMC from the clinical, pathological, immunohistochemical, and DFS aspects, the results of which are discussed. In our study, the average age of breast cancer was 8 years. In a similar study, Souza and colleagues reported that the average age of female dogs participated in the study was 10 years.[21] Medical studies show that the average

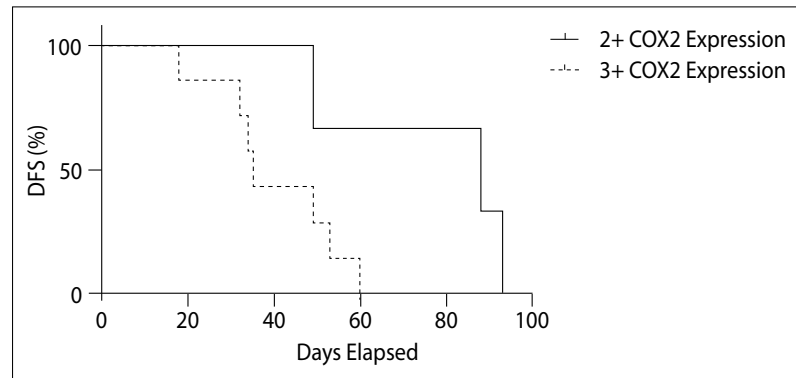

Fig. 3. Relationship between COX2 expression (graded as $2+$ and $3+$ ) and DFS (as days) in dogs with inflammatory mammary carcinoma. Although there was no significant relationship between the expression of grade 2 and grade 3 COX 2 enzyme with DFS, there was a tendency between the two. COX2: Cyclooxygenase 2, DFS: Disease-free survival. 
age of women with IBC is 57 years. [22] Some articles indicate that ages 8-10 in dogs are equivalent to ages 48-60 in humans.[23]

In terms of laterality, the tumors on the left side were slightly larger than on the right. This is also mentioned in breast cancer in women, but its biological causes have not yet been elucidated.[24] In our study, the mean tumor size was $4.2 \pm 1.0 \mathrm{~cm}$, and most studies have shown that the IMC and IBC sizes are larger because of the biological nature of this type of cancer cell, it is found to be poorly cohesive and in some cases does not form a solid mass.[25] 40\% of the dogs in this study showed an attack on the lymph nodes. Scientific evidence suggests that the risk of lymph node involvement in IBC is high.[26,27] Pathological evaluation of lymph nodes is still one of the important challenges of TNM staging in pet oncology and, unlike human oncology, surgical protocols and pathological evaluation of lymph nodes has not yet been developed.[28]

Microscopic studies showed that more than $90 \%$ of IMC tumors were tubular and tubulo-papillary carcinomas and were in grade II-III. Our findings were consistent with many studies on dogs and women, i.e., in most cases the tumor grade is high at the time of diagnosis.[3,5] Dermal lymphatic invasion (DLI), which is one of the hallmarks of IMC pathology and IBC was reported to be $100 \%$ positive for DLI in our samples. $70 \%$ of the margins in this study were free, probably due to the type of surgery. $60 \%$ of the dogs had unilateral mastectomy. However, despite the cleanliness of surgical margins, local recurrence often occurred. The biological nature of breast cancer seems to be different from other types of cancers. The poor nature of cohesiveness causes the misidentification of the malignant cells of single margins in $\mathrm{H} \& \mathrm{E}$ staining,[29] so it is also recommended to use IHC staining to evaluate surgical margins in IMC patients.

An IHC study showed that $90 \%$ of the tumors studied lacked hormonal receptors (90\% had a negative ER and $100 \%$ had a negative PR). On the other hand, HER2 was reported to be $70 \%$ positive. Scientific evidence suggests that the lack of hormonal receptors and positive HER2 increase the invasive potency of breast cancer.[30]

A study with Ki67 showed that $100 \%$ of the tumors were highly proliferated, and this alone indicates that the IMC was aggressive. Ning and colleagues studied 257 women with stage III IBC and concluded that the average Ki67 was higher than $48 \%$ and had a significant relationship with the reduction of overall survival.[31] Our study on dogs with IMC was in line with human studies so that Ki67 was inversely related to diseasefree survival. Also, in our study, there was no relationship between tumor size and Ki67, which was probably related to IMC biology, so that the lack of solid mass formation caused an error in measuring tumor size.

From a molecular subtype point of view, more than $90 \%$ of tumors were in the HER 2 and triple-negative categories. Most studies in women show that most inflammatory breast cancers fall into these two categories.[15] However, research results at the National Oncology Institute (NIO) in 2018 differed from previous IBC findings.[32] It seems that determining the molecular subtype profile of this type of breast cancer requires further study.

p53, also known as the TP53 gene, was positive in $80 \%$ of the cases in this study. This biomarker is one of the most important control genes in the cell cycle; its wrong over-expression causes the loss of function of the control factor in the cell cycle. As a result, the prognosis of the patient becomes weaker.[33] In our study, there was no relationship between p53 and DFS, which is probably due to the low sample size.

COX2 enzyme, which is an inducible enzyme in cases of inflammation and tissue irritation, acts as a cancer-promoting agent in tumors. Most of the effects of this enzyme are attributed to prostaglandin E2 (PGE2).[34] PGE2 plays a key role in stimulating tumor angiogenesis and increases the mitosis coefficient35. The role of this enzyme and its overexpression in IBC and IMC is well described. Some believe that the therapeutic intervention of this enzyme may reduce the invasive power of the tumor in inflammatory cancers.[35] In our study, $100 \%$ of patients showed moderate to high expression of this enzyme.

The statistical results of this study showed that there was no significant correlation between the expression of $\mathrm{COX}_{2}^{++}$and $\mathrm{COX} 2^{+++}$with DFS, although according to Figure 3, there is a tendency between COX2 and DFS enzyme expression. It is possible that if the sample size of the study was large, there would be a significant correlation. Lack of expression of COX2 enzyme in our studied tumors indicates the possible role of COX2 selective inhibitors in disease control or survival improvement. In this regard, it is suggested that further studies should be conducted about this subject in the field of comparative oncology.

The limitations of this study were the low sample size and lack of access to patients' overall survival rates. In pet oncology, measuring the overall survival rate cannot be accurate as the animals are euthanized at the end-stage due to moral considerations. The DFS is said 
to be a possible surrogate for the overall survival rate in estimating survival rates.[36]

Over time, the value of comparative oncology increases and the influence of the science pet oncology over human oncology becomes more prominent every day. Previous studies have shown the similarities between IBC in women and IMC in female dogs. In this study, we studied the clinical, pathological, and immunohistochemical aspects of IMC dogs and followed them and obtained their DFS. Our results showed that canine IMC is similar to women's IBC in many biological and clinical aspects. However, molecular studies are not yet sufficient in the field of dogs' IMC.

It is suggested that, by initiating clinical trials, the therapeutic value of $\mathrm{COX}_{2}$ enzyme inhibition and other genes involved in the molecular pathway, the production of this inflammatory mediator in IMC should be studied. This would be an important step taken toward comparative oncology goals. Multidisciplinary team studies between various animal oncology specialists and intra-disciplinary medical oncology teams will improve the treatment of pet animal cancers and the results may be extended to human cancer.

Acknowledgement: The authors express their gratitude to Dr. Ahad Muhammadnajad, a pathologist at the Cancer Research Center of Tehran University of Medical Sciences, who has helped with all stages of the study.

Peer-review: Externally peer-reviewed.

Conflict of Interest: All authors declared no conflict of interest.

Ethics Committee Approval: The ethical committee approval was received from the Ethics Committee of Islamic Azad University - Science \& Research Branch (Tehran, Iran) with the protocol number of 930139779 and the decision number of IR.IAU.SRB.REC.1398.180.

Financial Support: The project was financed by Sanaz Rismanchi, as a self-financing $\mathrm{PhD}$ student.

Authorship contributions: Concept - P.M., S.R.; Design - S.M., S.R.; Supervision - P.M.; Funding - S.R.; Materials S.R.; Data collection and/or processing - S.R.; Data analysis and/or interpretation - S.M.; Literature search - S.R.; Writing - S.R.; Critical review - P.M.

\section{References}

1. Biswas T, Jindal C, Fitzgerald TL, Efird JT. Pathologic Complete Response (pCR) and Survival of Women with Inflammatory Breast Cancer (IBC): An Analysis Based on Biologic Subtypes and Demographic
Characteristics. Int J Environ Res Public Health 2019;16(1):124.

2. van Uden DJ, van Laarhoven HW, Westenberg AH, de Wilt $\mathrm{JH}$, Blanken-Peeters $\mathrm{CF}$. Inflammatory breast cancer: an overview. Crit Rev Oncol Hematol 2015;93(2):116-26.

3. Cserni G, Charafe-Jauffret E, van Diest PJ. Inflammatory breast cancer: The pathologists' perspective. Eur J Surg Oncol 2018;44(8):1128-34.

4. Abramowitz MC, Li T, Morrow M, Sigurdson ER, Anderson P, Nicolaou N, et al. Dermal lymphatic invasion and inflammatory breast cancer are independent predictors of outcome after postmastectomy radiation. Am J Clin Oncol 2009;32(1):30-3.

5. Raghav K, French JT, Ueno NT, Lei X, Krishnamurthy S, Reuben JM, et al. Inflammatory Breast Cancer: A Distinct Clinicopathological Entity Transcending Histological Distinction. PLoS One 2016;11(1):e0145534.

6. Mamouch F, Berrada N, Aoullay Z, El Khanoussi B, Errihani H. Inflammatory Breast Cancer: A Literature Review. World J Oncol 2018;9(5-6):129-35.

7. Ismaili N, Elyaakoubi H, Bensouda Y, Errihani H. Demographic, clinical, pathological, molecular, treatment characteristics and outcomes of nonmetastatic inflammatory breast cancer in Morocco: 2007 and 2008. Exp Hematol Oncol 2014;3:1.

8. Li J, Xia Y, Wu Q, Zhu S, Chen C, Yang W, et al. Outcomes of patients with inflammatory breast cancer by hormone receptor- and HER2-defined molecular subtypes: A population-based study from the SEER program. Oncotarget 2017;8(30):49370-9.

9. Lim B, Woodward WA, Wang X, Reuben JM, Ueno NT. Inflammatory breast cancer biology: the tumour microenvironment is key. Nat Rev Cancer 2018;18(8):485-99.

10. Fouad TM, Kogawa T, Reuben JM, Ueno NT. The role of inflammation in inflammatory breast cancer. Adv Exp Med Biol 2014;816:53-73.

11. Morales J, Alpaugh ML. Gain in cellular organization of inflammatory breast cancer: A 3D in vitro model that mimics the in vivo metastasis. BMC Cancer 2009;9:462.

12. Wurth R, Tarn K, Jernigan D, Fernandez SV, Cristofanilli M, Fatatis A, et al. A Preclinical Model of Inflammatory Breast Cancer to Study the Involvement of CXCR4 and ACKR3 in the Metastatic Process. Transl Oncol 2015;8(5):358-67.

13. Holen I, Speirs V, Morrissey B, Blyth K. In vivo models in breast cancer research: progress, challenges and future directions. Dis Model Mech 2017;10(4):359-71.

14. Abdelmegeed SM, Mohammed S. Canine mammary tumors as a model for human disease. Oncol Lett 2018;15(6):8195-205.

15. Goldschmidt M, Peña L, Rasotto R, Zappulli V. Classi- 
fication and grading of canine mammary tumors. Vet Pathol 2011;48(1):117-31.

16. Raposo TP, Arias-Pulido H, Chaher N, Fiering SN, Argyle DJ, Prada J, et al. Comparative aspects of canine and human inflammatory breast cancer. Semin Oncol 2017;44(4):288-300.

17. Baioni E, Scanziani E, Vincenti MC, Leschiera M, Bozzetta E, Pezzolato M, et al. Estimating canine cancer incidence: findings from a population-based tumour registry in northwestern Italy. BMC Vet Res 2017;13(1):203.

18. Fouad TM, Barrera AMG, Reuben JM, Lucci A, Woodward WA, Stauder MC, et al. Inflammatory breast cancer: a proposed conceptual shift in the UICC-AJCC TNM staging system. Lancet Oncol 2017;18(4):e228e32.

19. Dawood S, Lei X, Dent R, Gupta S, Sirohi B, Cortes J, et al. Survival of women with inflammatory breast cancer: a large population-based study. Ann Oncol 2014;25(6):1143-51.

20. Peña L, Perez-Alenza MD, Rodriguez-Bertos A, Nieto A. Canine inflammatory mammary carcinoma: histopathology, immunohistochemistry and clinical implications of 21 cases. Breast Cancer Res Treat 2003;78(2):141-8.

21. de M Souza CH, Toledo-Piza E, Amorin R, Barboza A, Tobias KM. Inflammatory mammary carcinoma in 12 dogs: clinical features, cyclooxygenase- 2 expression, and response to piroxicam treatment. Can Vet J 2009;50(5):506-10.

22. Anderson WF, Schairer C, Chen BE, Hance KW, Levine PH. Epidemiology of inflammatory breast cancer (IBC). Breast Dis 2005-2006;22:9-23.

23. Queiroga FL, Raposo T, Carvalho MI, Prada J, Pires I. Canine mammary tumours as a model to study human breast cancer: most recent findings. In Vivo 2011;25(3):455-65.

24. Cheng SA, Liang LZ, Liang QL, Huang ZY, Peng XX, Hong XC, et al. Breast cancer laterality and molecular subtype likely share a common risk factor. Cancer Manag Res 2018;10:6549-54.

25. Kleer CG, van Golen KL, Braun T, Merajver SD. Persistent E-cadherin expression in inflammatory breast cancer. Mod Pathol 2001;14(5):458-64.

26. Chas M, Boivin L, Arbion F, Jourdan ML, Body G, Ouldamer L. Clinicopathologic predictors of lymph node metastasis in breast cancer patients according to molecular subtype. J Gynecol Obstet Hum Reprod 2018;47(1):9-15.

27. Wecsler JS, Tereffe W, Pedersen RC, Sieffert MR, Mack WJ, Cui $\mathrm{H}$, et al. Lymph node status in inflammatory breast cancer. Breast Cancer Res Treat 2015;151(1):113-20.

28. Muhammadnejad A, Keyhani E, Mortazavi P, Behjati F, Haghdoost IS. Overexpression of her-2/neu in malignant mammary tumors; translation of clinicopathological features from dog to human. Asian Pac J Cancer Prev 2012;13(12):6415-21.

29. Singletary SE. Surgical management of inflammatory breast cancer. Semin Oncol 2008;35(1):72-7.

30. Çakar B, Sürmeli Z, Öner PG, Yelim ES, Karabulut B, Uslu R. The Impact of Subtype Distribution in Inflammatory Breast Cancer Outcome. Eur J Breast Health 2018;14(4):211-7.

31. Ning J, Fouad TM, Lin H, Sahin AA, Lucci A, Woodward WA, et al. The impact of Ki-67 in the context of multidisciplinary care in primary inflammatory breast cancer. J Cancer 2019;10(12):2635-42.

32. Slaoui M, Zoure AA, Mouh FZ, Bensouda Y, El Mzibri M, Bakri Y, et al. Outcome of inflammatory breast cancer in Moroccan patients: clinical, molecular and pathological characteristics of 219 cases from the National Oncology Institute (INO). BMC Cancer 2018;18(1):713.

33. Bertheau P, Lehmann-Che J, Varna M, Dumay A, Poirot B, Porcher R, et al. p53 in breast cancer subtypes and new insights into response to chemotherapy. Breast 2013;22 (Suppl 2):S27-9.

34. Howe LR. Inflammation and breast cancer. Cyclooxygenase/prostaglandin signaling and breast cancer. Breast Cancer Res 2007;9(4):210.

35. Queiroga FL, Perez-Alenza MD, Silvan G, Peña L, Lopes C, Illera JC. Cox-2 levels in canine mammary tumors, including inflammatory mammary carcinoma: clinicopathological features and prognostic significance. Anticancer Res 2006;26(1a):446.

36. Saad ED, Squifflet P, Burzykowski T, Quinaux E, Delaloge S, Mavroudis D, et al. Disease-free survival as a surrogate for overall survival in patients with HER2-positive, early breast cancer in trials of adjuvant trastuzumab for up to 1 year: a systematic review and meta-analysis. Lancet Oncol 2019;20(3):361-70. 